\title{
Stroke Transiently Increases Subventricular Zone Cell Division from Asymmetric to Symmetric and Increases Neuronal Differentiation in the Adult Rat
}

\author{
Ruilan Zhang, ${ }^{1}$ Zhenggang Zhang, ${ }^{1}$ Chunling Zhang, ${ }^{1}$ Li Zhang, ${ }^{1}$ Adam Robin, ${ }^{1}$ Ying Wang, ${ }^{1}$ Mei Lu, ${ }^{2}$ and \\ Michael Chopp ${ }^{1,3}$ \\ Departments of ${ }^{1}$ Neurology and ${ }^{2}$ Biostatistics and Research Epidemiology, Henry Ford Health Sciences Center, Detroit, Michigan 48202, and ${ }^{3}$ Department \\ of Physics, Oakland University, Rochester, Michigan 48309
}

\begin{abstract}
The orientation of mitotic cleavage regulates neurogenesis during neural development. We examined the orientation of mitotic cleavage of dividing progenitor cells in the subventricular zone (SVZ) of adult rats subjected to stroke. In nonstroke rats, $55 \%$ of dividing cells were oriented horizontally, whereas $40 \%$ were oriented vertically. Horizontal and vertical cleavage orientations produce asymmetric and symmetric divisions, respectively. Four days after stroke, the number of dividing cells increased twofold, whereas the proportion of symmetric dividing cells significantly $(p<0.01$ ) increased from $40 \%$ before stroke to $60 \%$. Fourteen days after stroke, the percentage of symmetric dividing cells was $47 \%$. Stroke-increased numbers of dividing cells in M-phase were confirmed by immuostaining. In nonstroke rats, 37 and $33 \%$ of symmetric and asymmetric dividing cells, respectively, exhibited a neuronal marker (TuJ1). Four days after stroke, rats exhibited a significant $(p<0.05)$ augmentation of the frequency ( $47 \%$ ) of neuronal distribution showing TuJ1 immunoreactivity in cells with symmetric division but not cells with asymmetric division (33\%). Numb immunoreactivity was detected in SVZ cells of nonstroke rats. Stroke did not change Numb distribution. Our data suggest that neurons are produced by both asymmetric and symmetric cell divisions in the adult SVZ, and the transient increases in symmetric division and neuronal differentiation may result in stroke-induced neurogenesis.
\end{abstract}

Key words: focal cerebral ischemia; cell division; neural progenitor cells; subventricular zone; mitosis; rats

\section{Introduction}

During embryonic neurogenesis, replication of DNA in cells is accomplished in the outer (basal) segment of the ventricular zone (VZ) (Hinds and Ruffett, 1971; Chenn and McConnell, 1995). DNA replication then moves to the apical VZ to undergo mitosis toward the ventricular surface (Hinds and Ruffett, 1971; Chenn and McConnell, 1995). This interkinetic nuclear migration (INM) model results in symmetric and asymmetric divisions of neuronal precursors (Chenn and McConnell, 1995). The orientation of mitotic cleavage regulates the production of neurons (Langman et al., 1966; Martin, 1967; McConnell, 1995). Vertical cleavages produce symmetric division to generate two identical daughter cells that stay in the VZ to maintain the progenitor pool (Berry and Rogers, 1965; Smart, 1973). Horizontal cleavages produce asymmetric division to generate two distinct daughter cells. The apical daughter maintains progenitor identity, whereas the basal daughter becomes a young migratory neuron that migrates away from the VZ to the cortical plate (Chenn and McConnell, 1995). As embryonic neurogenesis comes to an end, the VZ is

Received Dec. 22, 2003; revised May 12, 2004; accepted May 12, 2004.

This work was supported by National Institute of Neurological Disorders and Stroke Grants P01 NS23393, P01 NS42345, R01NS38292, and R01HL 64766 .

Correspondence should be addressed to Dr. Michael Chopp, Department of Neurology, Henry Ford Hospital, 2799 West Grand Boulevard, Detroit, MI 48202. E-mail: chopp@neuro.hfh.edu.

DOI:10.1523/JNEUROSCI.1109-04.2004

Copyright $\odot 2004$ Society for Neuroscience $\quad$ 0270-6474/04/245810-06\$15.00/0 replaced by an ependymal layer while the subventricular zone (SVZ) shrinks and persists as the subependyma (Morshead et al., 1998). The adult SVZ contains neural stem and progenitor cells that generate neurons and glia throughout adulthood (Luskin, 1993; Lois and Alvarez-Buylla, 1994). Recent studies show evidence that INM of progenitor cells persists in the adult brain (Alvarez-Buylla et al., 1998; Tramontin et al., 2003). In adult canaries, Alvarez-Buylla et al. (1998) identified INM of precursor cells during neurogenesis within the VZ. The same group demonstrates that a germinal layer with characteristics similar to those of the embryonic VZ persists in the young adult mouse SVZ (Tramontin et al., 2003). Demonstration that cells in the adult SVZ display INM and serve as progenitors of new neurons supports a possible role for the orientation of mitotic cleavage in neurogenesis in the adult brain.

Numb is a membrane-associated signaling protein that is expressed by neuroblasts (Zhong et al., 1996; Cayouette et al., 2001). Asymmetric segregation of Numb in progenitor cells has an important role in generating asymmetric cell divisions and diverse cell fates during mouse cortical development (Zhong et al., 1997; Petersen et al., 2002). Overexpression of Numb in chick CNS enhances progenitor proliferation (Wakamatsu et al., 1999), and Numb mutant mice have impaired neuronal differentiation and die during the embryonic stage (Zhong et al., 2000).

We and others demonstrated that stroke induces neurogenesis in the SVZ (Zhang et al., 2001; Arvidsson et al., 2002; Parent et al., 
2002; Jin et al., 2003; Zhang et al., 2004). Given roles for the orientation of mitotic cleavage in regulating neurogenesis and Numb expression in generating asymmetric cell divisions, we examined the behavior of dividing progenitor cells and Numb expression in the SVZ of adult rats subjected to stroke. Our results indicate that stroke transiently increases SVZ cell division from asymmetric to symmetric without a change in Numb distribution, suggesting that symmetric division results in an expanding pool of progenitor cells, which may contribute to strokeincreased neurogenesis.

\section{Materials and Methods}

All experimental procedures have been approved by Henry Ford Hospital Institutional Animal Care and Use Committee. All efforts were made to minimize the number of animals used and their suffering.

Animal model of stroke. Male Wistar rats (3-4 months of age) were used. The right middle cerebral artery (MCA) was occluded by placement of an embolus at the origin of the MCA (Zhang et al., 1997).

Histology and determination orientation of mitotic cleavage. Rats $(n=$ 31 ) at 4, 7, 14, and $28 \mathrm{~d}$ after MCA occlusion were transcardially perfused with heparinized saline followed by $4 \%$ paraformaldehyde. Brains were fixed in $4 \%$ paraformaldehyde and embedded in paraffin. Nonischemic rats $(n=8)$ were used as a control group. In our preliminary experiments, numbers of bromodeoxyuridine (BrdU)-positive cells and dividing cells in the contralateral SVZ were not significantly different from numbers in nonischemic rats. Semithin coronal sections $(1 \mu \mathrm{m})$ of the lateral ventricles (LVs) were cut at the level of anteroposterior (AP) plus $10.2 \mathrm{~mm}$ (genu corpus callosum) and AP plus $9.20 \mathrm{~mm}$ (anterior commissure crossing) (Paxinos and Watson, 1986). Every 60th coronal section for a total of four sections per rat was stained with hematoxylin and eosin for analysis of cleavage orientations in dividing subventricular zone cells. The whole SVZ was digitized under a $100 \times$ objective (Olympus BX40; Olympus Optical, Tokyo, Japan) via the MicroComputer Imaging Device (MCID; Imaging Research, St. Catharines, Canada). The number of the mitotic cells and the angle of mitotic cleavage relative to the lateral ventricular surface were measured using the MCID system. The dividing cells in the SVZ are presented as the total number of mitotic cells of the four sections. Distribution of mitotic cleavage is presented as a percentage that is based on the total numbers of dividing cells.

Position of BrdU-labeled cells in the LV wall. Nonischemic rats receiving a single dose of $\operatorname{BrdU}(100 \mathrm{mg} / \mathrm{kg}$, i.p.) were killed 1, 5, 7, and $11 \mathrm{hr}(n=$ 4 per time point) after the injection. For each rat, every 50th paraffinembedded coronal section ( $1 \mu \mathrm{m}$ thick) for a total of four sections encompassing the lateral ventricles was immunostained with an antibody against BrdU. Forty to sixty BrdU-labeled cells in the SVZ per rat were mapped under a $100 \times$ objective, and the distance from the center of BrdU-labeled nucleus in the SVZ to the lateral ventricle surface was measured using the MCID system by experimenters blinded to the time point after stroke of each animal.

Immunohistochemistry. Single or double immunofluorescent staining for brain tissue was performed on paraffin-embedded coronal sections ( 6 $\mu \mathrm{m}$ ) as described previously (Zhang et al., 2004). The following primary antibodies were used in the present study: mouse anti-BrdU (1:1000; Roche Diagnostics, Indianapolis, IN), mouse anti- $\beta$-tubulin III (TuJ1; 1:1000; Novus Biologicals, Littleton, CO), rabbit polyclonal antiphospho-Histone H3 antibody (1:1000; Upstate Biotechnology, Lake Placid, NY), and rabbit polyclonal anti-Numb antibody (1:200; Upstate Biotechnology, Lake Placid, NY). For BrdU immunostaining, DNA was first denatured by incubating coronal sections in $50 \%$ formamide $2 \times$ SSC at $65^{\circ} \mathrm{C}$ for $2 \mathrm{hr}$ and then in $2 \mathrm{~N} \mathrm{HCl}$ at $37^{\circ} \mathrm{C}$ for $30 \mathrm{~min}$ (Zhang et al., 2001). Sections were incubated with the anti-BrdU antibody overnight and incubated with biotinylated secondary antibody (1:200; Vector Laboratories, Burlingame, CA) for $1 \mathrm{hr}$. Reaction product was detected using 3'3'-diaminobenzidine-tetrahydrochloride (Sigma, St. Louis, MO).

Statistics. All values are presented as mean \pm SE. Repeated measure ANOVA was used to study the stroke effect on cell orientations compared with nonischemic controls, including the repeated factor of cleavage orientation-distribution in three categories and indepen-
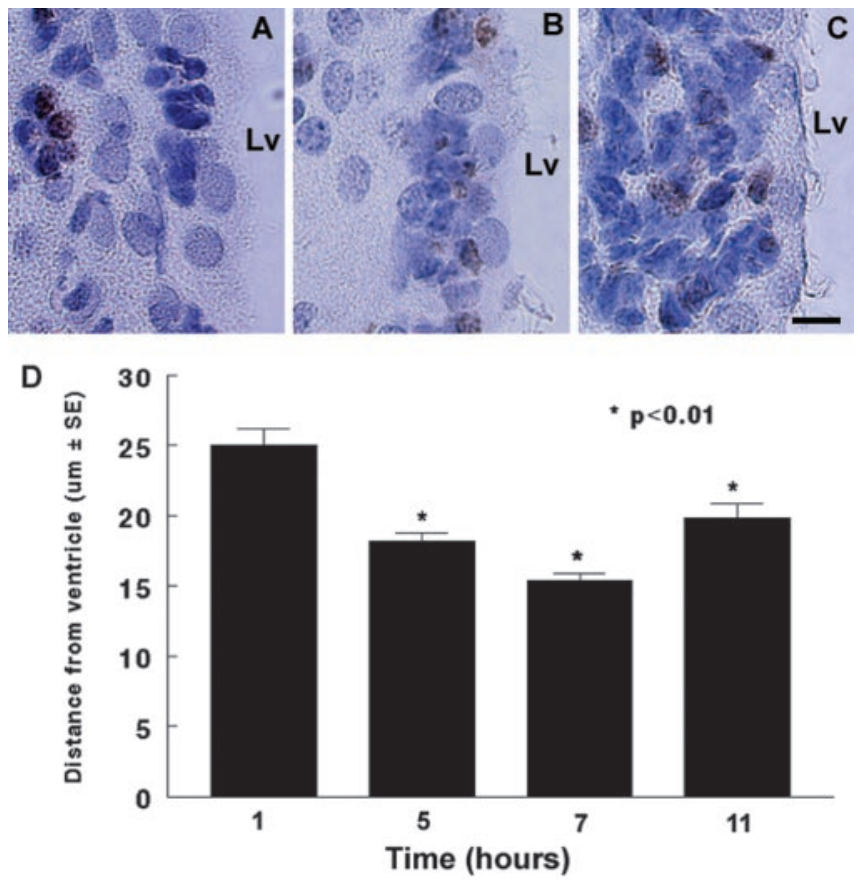

Figure 1. Distribution of BrdU-immunoreactive cells in the SVZ after a single injection of BrdU. A, One hour after injection of BrdU, BrdU-immunoreactive cells were localized in the SVZ distant from the lateral ventricular surface. B, Five hours after the injection, BrdUimmunoreactive cells were detected adjacent to the lateral ventricle. C, Eleven hours after the injection, BrdU-immunoreactive cells were found throughout the SVZ. D, The distance changes at 5 and $11 \mathrm{hr}$ were significant compared with the distance measured at $1 \mathrm{hr}$ after the injection. Lv, Lateral ventricle. Scale bar: $A-C, 10 \mu \mathrm{m}$.

dent factors of stroke type (stroke vs nonstroke). Statistical significance was set at $p<0.05$.

\section{Results}

The position of BrdU-labeled cells in the SVZ

BrdU is incorporated into the DNA of dividing cells during the S-phase of cell division. To examine whether dividing cells move in the SVZ, distances between BrdU-labeled nuclei and the lateral ventricle surface were measured at $1,5,7$, and $11 \mathrm{hr}$ after single injection of BrdU. One hour after the injection, BrdU immunoreactive cells were detected in the SVZ with a distance of $25 \pm 1.1$ $\mu \mathrm{m}(n=4)$ from the lateral ventricular surface (Fig. $1 A, D)$. Five (Fig. $1 B$ ) and $7 \mathrm{hr}$ after the injection, distances of BrdU-labeled nuclei from the ventricular lumen were $18 \pm 0.5(n=4)$ and $14 \pm$ $0.5 \mu \mathrm{m}(n=4)$, respectively, which are statistically significant $(p<0.01)$ compared with the distance in the $1 \mathrm{hr}$ group, indicating that labeled cells in the SVZ move progressively closer to the ventricle surface. However, $11 \mathrm{hr}$ after injection (Fig. 1C,D), although numbers of BrdU immunoreactive cells increased, distances of BrdU-positive cells from the ventricular lumen were $20 \pm 1.0 \mu \mathrm{m}(n=4)$.

\section{Cleavage orientation of cells in nonstroke SVZ}

To examine cleavage orientations in dividing cells in the SVZ, the angle of mitotic cells was measured at a variety of orientations: vertical or perpendicular to the ventricular surface (Fig. $2 A$ ), horizontal or parallel to the luminal surface (Fig. $2 B$ ), and intermediate (oblique) (Fig. 2C). Although cells in the metaphase were detected in the present study (data not shown), these cells were excluded from the analysis because metaphase plates could rotate before division and might have altered the orientation of their cleavage to segregate cell-fate determinants (Chenn and 


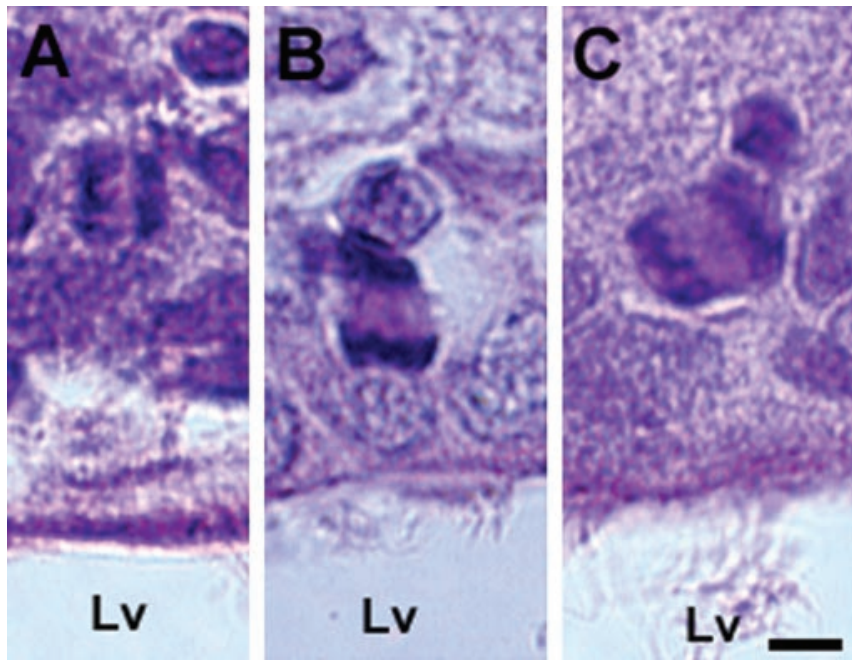

Figure 2. Cleavage orientations of dividing cells in the SVZ. A-C show mitotic cells with vertical, horizontal, and oblique nuclei, respectively, to the lateral ventricular surface. Lv, Lateral ventricle. Scale bar, $5 \mu \mathrm{m}$.

McConnell, 1995; Cayouette et al., 2001). The orientations of cleavage were tabulated for 96 mitotic cells from eight nonstroke rats (Table 1). Of 96 dividing cells examined, 55\% were oriented horizontally $\left(0-30^{\circ}\right)$ (Fig. 2 B, Table 1 ), $40 \%$ were oriented vertically $\left(60-90^{\circ}\right)$ (Fig. $2 A$, Table 1$)$, and remaining cleavages were oriented intermediately $\left(30-60^{\circ}\right)$ (Fig. $2 C$, Table 1$)$. Horizontal and vertical cleavage orientations produce asymmetric and symmetric divisions, respectively (Chenn and McConnell, 1995). Thus, these data indicate that the asymmetric division is dominant in the nonstroke adult SVZ.

\section{Cleavage orientation of cells in stroke SVZ}

Stroke significantly $(p<0.05)$ increased numbers of mitotic cells in the ipsilateral SVZ at $4 \mathrm{~d}$ (156), $7 \mathrm{~d}$ (267), and $14 \mathrm{~d}$ (216) after stroke compared with numbers in nonstroke (96), which is consistent with previous studies (Zhang et al., 2001). To examine whether stroke affects cleavage orientation of these dividing cells, cleavage orientation was measured. At 4 and $7 \mathrm{~d}$ after stroke, 35 and $40 \%$ of dividing cells, respectively, exhibited horizontal orientation (Table 1), which are significantly $(p<0.01)$ lower than the percentage in nonstroke rats $(55 \%)$. In contrast, at the same time period, the percentage of dividing cells with vertical orientation significantly $(p<0.05)$ increased from $40 \%$ in nonstroke to $60 \%$ at $4 \mathrm{~d}$ and $54 \%$ at $7 \mathrm{~d}$ after stroke (Table 1). These data indicate that the ipsilateral SVZ cells significantly increase symmetric division during 4-7 d after stroke (Table 1). At 14 and $28 \mathrm{~d}$ after stroke, 47 and $50 \%$ of dividing cells were horizontal, respectively, which is close to the level of asymmetric division in nonstroke rats (Table 1).

\section{Cleavage orientation of dividing cells and neuronal differentiation}

Asymmetric division is associated with neuronal differentiation (Chenn and McConnell, 1995; Shen et al., 2002). Using $\beta$-tubulin III (TuJ1) as a marker for immature neurons (Memberg and Hall, 1995), we assayed cleavage orientation and TuJ1 immunoreactive cells in nonstroke $(n=4), 4 \mathrm{~d}$ stroke $(n=4)$, and $7 \mathrm{~d}$ stroke $(n=$ 4) rats. To detect the earliest differentiation time, cells with anaphase, metaphase, and telophase were analyzed. Cells with mitotic bodies in late anaphase and telophase but not in metaphase were TuJ1 positive (Fig. $3 A, B$ ). In nonstroke SVZ, of 19 cells with symmetric division, 10.5 and $31.6 \%$ were TuJ1 immunoreactive at one and both (Fig. 3D) borders, respectively, and the remaining cells were TuJ1 negative (Fig. 3D). Of 27 cells with asymmetric division, 12 and 56\% had TuJ1 immunoreactivity at one border near and distant from the lateral ventricle, respectively, and $32 \%$ were TuJ1-negative cells (Fig. $3 E$ ). In the $4 \mathrm{~d}$ stroke SVZ, of 54 cells with symmetric division, 15.2 and $39.2 \%$ had TuJ1 immunoreactivity at one and both borders (Fig. 3D), respectively, and the remaining cells were $\mathrm{Tu} 1 \mathrm{l}$ negative (Fig. $3 D$ ). The percentage of total TuJ1-positive cells with symmetric divisions $4 \mathrm{~d}$ after stroke $(15.2 / 2+39.2=46.8)$ was significantly $(p<0.05)$ higher than the percentage in nonstroke animals $(10.5 / 2+31.6=36.9)$. In the $4 \mathrm{~d}$ stroke SVZ, of 31 cells with asymmetric division, 10.8 and $54.6 \%$ had TuJ1 immunoreactivity at one border near and distant from the lateral ventricle, respectively, and $34.6 \%$ were TuJ1-negative cells (Fig. 3E). The percentage of total TuJ1positive cells with asymmetric divisions $(10.8 / 2+54.6 / 2=32.7)$ in the $4 \mathrm{~d}$ stroke SVZ was not significantly different from the percentage in the nonstroke SVZ $(12 / 2+56 / 2=34)$ (Fig. $3 E)$. In the $7 \mathrm{~d}$ stroke SVZ, the percentage of TuJ1-positive cells with symmetrical division was not significantly different from the percentage in the nonstroke SVZ (Fig. 3D). To examine whether $\mathrm{TuJ} 1$-positive cells were terminally differentiated, double immunostaining with antibodies against $\mathrm{TuJ} 1$ and $\mathrm{Ki} 67$ was performed. We found that $15 \pm 3.1 \%(n=6)$ of TuJ1-positive cells were Ki67 immunoreactive (supplemental Fig. 1, available at www.jneurosci. org), indicating that some neuroblasts are still able to proliferate, consistent with previous reports (Menezes et al., 1995).

\section{Stroke increases numbers of M-phase cells in adult SVZ}

To further confirm that stroke increases numbers of dividing cells, we examined phosphorylated histone H3 (HH3) expression, which is confined to cells in G2 to early telophase of the cell cycle (Hendzel et al., 1997). As expected, cells with condensed $\mathrm{HH} 3$ nuclear staining were detected in the nonstroke SVZ (Fig. $4 A$, arrow, $C$ ), indicating that these cells are in M-phase (Hendzel et al., 1997). Quantitative analysis revealed that numbers of HH3positive cells in the ipsilateral SVZ significantly $(p<0.05)$ increased at 4, 7, and $14 \mathrm{~d}$ after stroke (Fig. $4 B$, arrows, $C$ ). Numbers of $\mathrm{HH} 3$-positive cells with mitotic morphology were $\sim 10$ times less than numbers of total $\mathrm{HH} 3$-positive cells, although the temporal profile was generally the same (Fig. $4 C$ ), suggesting that the measurement of mitosis according to cellular morphology is underestimated.

\section{Numb protein expression in adult brain}

Overexpression of Numb increases differentiation of neural stem cells into neurons during embryonic development (Wakamatsu et al., 1999). We examined Numb distribution in the adult brain. In nonstroke brain, cells in the SVZ and ependyma cells were Numb immunoreactive (Fig. 5A, green), and Numb-positive cells were TuJ1 negative (Fig. $5 A$, red). In addition, Numb immunoreactivity was detected in mitotic cells (Fig. $5 B$ ). Stroke did not change the distribution of Numb immunoreactivity.

\section{Discussion}

The present study demonstrates that stroke transiently increases cleavage orientation of dividing adult SVZ cells from horizontal to vertical orientation, indicating that cell divisions change from asymmetric to symmetric. In addition, stroke increases neuronal differentiation during increased symmetric division. Symmetric division is coincident with significant increases in 
Table 1. Percentage of cleavage orientation of dividing cells

\begin{tabular}{|c|c|c|c|c|c|}
\hline \multirow{2}{*}{$\begin{array}{l}\text { Cleavage } \\
\text { orientation }\end{array}$} & \multirow[b]{2}{*}{ No-stroke $(n=8)$} & \multicolumn{4}{|l|}{ Stroke (days) } \\
\hline & & $4(n=7)$ & $7(n=8)$ & $14(n=8)$ & $28(n=8)$ \\
\hline$\ominus$ & 55 (53 of 96$)$ & 35 (54 of 156) & 40 (108 of 267) & 47 (101 of 216) & 50 (61 of 121$)$ \\
\hline$\varnothing$ & $5(5$ of 96$)$ & $5(8$ of 156$)$ & 6 (15 of 267) & 6 (12 of 216$)$ & 5 (6 of 121) \\
\hline (1) & 40 (38 of 96$)$ & 60 (94 of 156) & 54 (144 of 267) & 48 (103 of 216$)$ & 45 (54 of 121) \\
\hline
\end{tabular}

Numbers in parentheses indicate actual cell numbers.

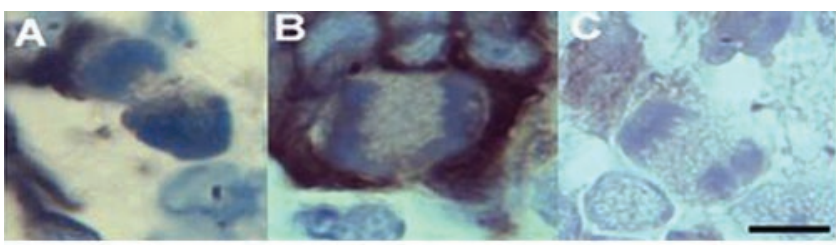

D

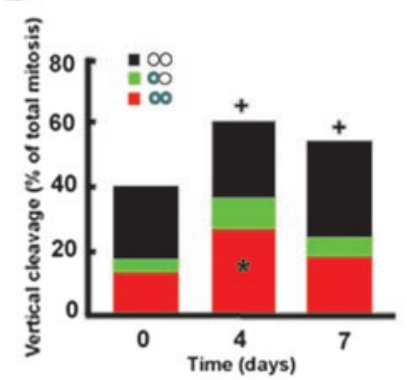

E

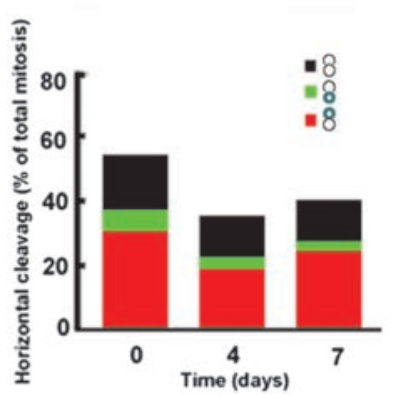

Figure 3. Distribution of TuJ1 immunoreactivity in dividing cells. $A-C$, Micrographs show TuJ1 immunoreactivity at basal $(A)$ or both $(B)$ borders of dividing cells and a TuJ1-negative dividing cell ( $C$. $D$ and $E$ show the percentage of the distribution of TuJ1-positive or -negative immunoreactivity relative to different vertical and horizontal cleavage orientation, respectively, during cell division from nonstroke and stroke rats. Each pair circle represents a mitotic cell with the orientation of the cell cleavage plane referenced to the SVZ. Green color in circles indicates the presence of TuJ1 immunoreactivity. Time points indicate days after stroke. ${ }^{+} p<$ 0.05 represents total percentage of vertical cleavage orientation at 4 and $7 \mathrm{~d}$ versus total percentage at $0 \mathrm{~d}$. ${ }^{*} p<0.05$ represents percentage of TuJ1 immunoreactivity of total vertical cleavage $4 \mathrm{~d}$ after stroke versus percentage of TuJ1 immunoreactivity at $0 \mathrm{~d}$. Scale bar, $10 \mu \mathrm{m}$. $n=4$ for each time point.

numbers of proliferating SVZ cells, suggesting that symmetric division, which expands the pool of progenitor cells, and increased neuronal differentiation may contribute to strokeincreased neurogenesis.

In embryos, stem cells in the VZ undergo INM, which results in symmetric and asymmetric divisions (Hinds and Ruffett, 1971; Chenn and McConnell, 1995; Alvarez-Buylla et al., 1998). Recent studies of adult canaries and mice show evidence that nuclear migration of progenitor cells remains in the adult SVZ (AlvarezBuylla et al., 1998; Tramontin et al., 2003). Our data show that BrdU-labeled cells in the adult SVZ were localized to different distances from the lateral ventricular surface during 1-11 hr after a single injection of BrdU. The BrdU-labeled cells were closer to the ventricular surface at 5 and $7 \mathrm{hr}$ than the BrdU-labeled cells at 1 and 11 hr after injection. These observations suggest that dividing cells in the adult SVZ move and may behave as in interkinetic nuclear migration.

The orientation of mitotic cleavage regulates the production of neurons (Chenn and McConnell, 1995). Vertical and horizontal cleavages produce symmetric and asymmetric divisions, respectively (Smart, 1973; Chenn and McConnell, 1995). In early development, symmetric divisions dominate dividing cells in the $\mathrm{VZ}$, which serves to expand the progenitor pool, whereas asymmetric division increases neuronal production (Smart, 1973;
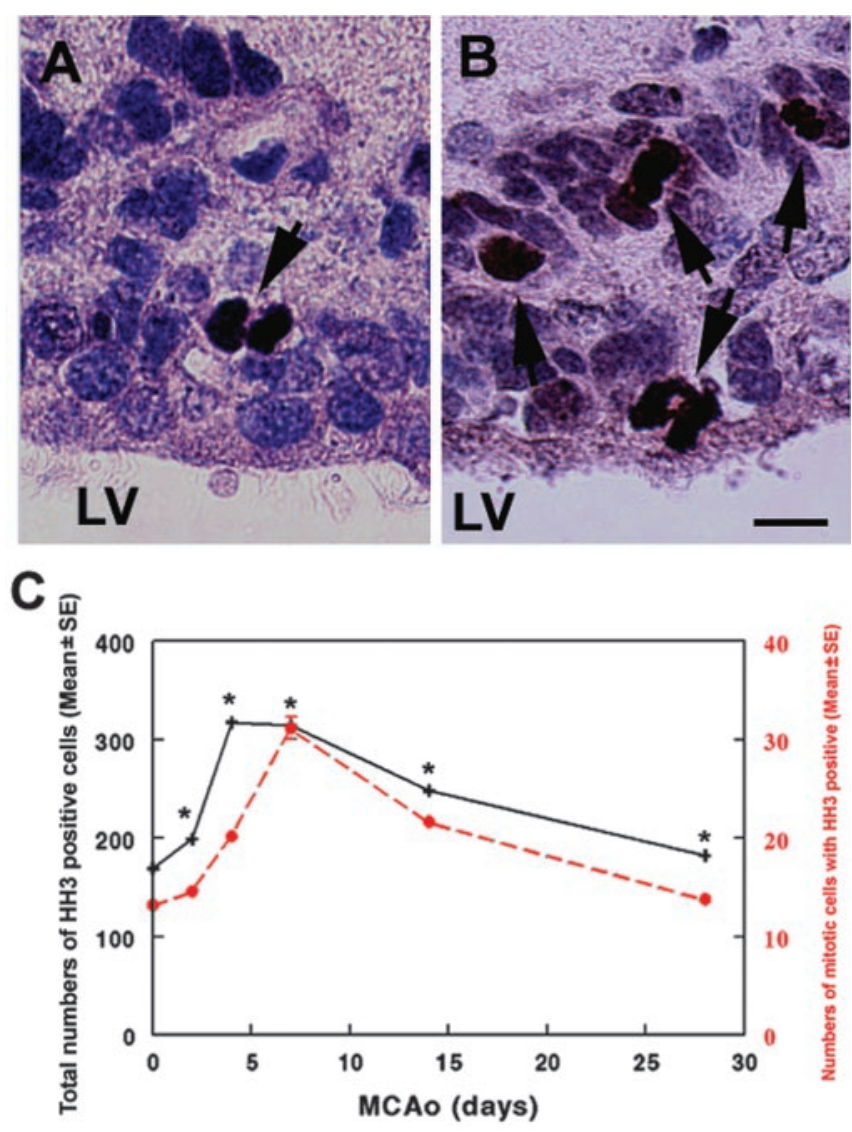

Figure 4. $\mathrm{HH} 3$ immunoreactivity. $A$ and $B$ show $\mathrm{HH} 3$ immunoreactivity in dividing $\mathrm{SVZ}$ cells (arrows) in nonstroke and $4 \mathrm{~d}$ stroke rats, respectively. $C$ is a line graph showing quantitative analysis of numbers of $\mathrm{HH} 3$ immunopositive cells (black line) and numbers of HH3-positive cells with mitotic divisions (red line) at $0,4,7$, and 14 d after stroke ( $n=4$ for each time point). ${ }^{*} p<$ 0.05 versus the number at $0 \mathrm{~d}$. Lv, Lateral ventricle. Scale bar, $10 \mu \mathrm{m}$.

Caviness et al., 1995; Chenn and McConnell, 1995). The adult mammalian SVZ contains relatively quiescent neural stem cells that divide asymmetrically and give rise to constitutively proliferating progenitor cells throughout animal life (Morshead et al., 1998). One of the progeny of each active division undergoes cell death or migrates and differentiates into a neuron in the olfactory bulb (Luskin, 1993; Lois and Alvarez-Buylla, 1994). Studies of cleavage orientation on living cells in brain slice culture demonstrate that the mitotic behavior of living cells is identical to those of cells examined in fixed brain sections (Chenn and McConnell, 1995). Our observation that the majority of dividing cells in fixed brain coronal sections were horizontally oriented in nonstroke SVZ suggests that asymmetric division dominates in the adult brain, which is consistent with findings that stem cells in the adult mouse SVZ retain their asymmetric division (Morshead et al., 1998). In addition, our data on the temporal profile of SVZ cell division show that stroke transiently increases numbers of vertically oriented dividing cells and decreases numbers of cells with 
horizontal orientation, suggesting that stroke transiently increases cell division from asymmetric to symmetric. Using time-lapse multiphoton microscopy, Haydar et al. (2003) demonstrated that spindle rotation in the dividing cells specifies the eventual cleavage orientation in responding to changes in the extracellular milieu in the mammalian neocortical VZ. Therefore, it is possible that transient increases in symmetric division result from, at least in part, stroke-induced changes in the SVZ environment. Additional work should clarify this possibility.

Increases in numbers of cells with symmetric division are concurrent with significant increases in numbers of proliferating SVZ cells. Although we have no direct evidence that the change in fraction of symmetric cell division observed in nonstroke and stroke accounts for stroke-increased numbers of proliferating SVZ cells, studies in developing cerebral cortex show that a fractional change of asymmetric cleavage before and during the period of neurogenesis contributes to the cortical neurogenesis (Chenn and McConnell, 1995). In addition to transient increases in symmetric division, stroke also increased the frequency $(47 \%)$ of neuronal phenotype in cells with symmetric division compared with the frequency (33\%) in cells with asymmetric division $4 \mathrm{~d}$ after stroke. Furthermore, $\mathrm{HH} 3 \mathrm{immu}-$ nostaining, which labels a histone phosphorylated in M-phase (Hendzel et al., 1997) revealed that our measurements of cleavage orientation of dividing cells on the basis of morphology only examined one-tenth of the dividing cells in M-phase. Symmetric cell divisions exponentially expand the progenitor pool (Smart, 1973; Caviness et al., 1995; Chenn and McConnell, 1995). Together, our data suggest that stroke-induced transient increases in symmetric dividing SVZ cells could contribute to increases in neuronal progenitor cells observed after stroke (Zhang et al., 2001; Arvidsson et al., 2002; Parent et al., 2002; Jin et al., 2003; Zhang et al., 2004). Consistent with our findings, others have shown that after depletion of actively proliferating cells in the adult SVZ with anti-mitotic agents or infusion of basic fibroblast growth factor and epidermal growth factor, neural stem cells undergo transient symmetric division to amplify the progenitor cell population (Craig et al., 1996; Morshead et al., 1998; Yoshimura et al., 2001; Nakatomi et al., 2002).

During development, different proportions of asymmetric, symmetric terminal, and symmetric nonterminal cell division coexist during the entire period of neurogenesis in the mouse (Cai et al., 2002). Progenitor cells in S-phase are plastic and capable of modifying their fate in response to environmental signals, but that in G2-mitosis, they become committed to a particular phenotype (McConnell and Kaznowski, 1991; Ericson et al., 1996; Belliveau and Cepko, 1999; Murciano et al., 2002). Our data show that some cells with symmetric divisions were TuJ1 immunoreactive, whereas other symmetric division cells were TuJ1 negative. Assuming that cells expressing neuronal markers represent cells that exit the cell cycle, although some TuJ1positive cells maintain the ability to divide (Menezes et al., 1995), our data indicate the presence of symmetric terminal cell division. Therefore, the adult SVZ contains asymmetric, symmetric terminal, and symmetric nonterminal cell divisions. Neurons are produced by both asymmetric and symmetric terminal cell divisions. The majority of TuJ1 immunoreactivity in dividing cells with asymmetric division were localized to the border distance from the lateral ventricle, indicating that these neuroblasts are poised to migrate from the SVZ. The observation of gradual increases in asymmetric division after stroke is consistent with our previous findings of significant increases in the numbers of migrating neuroblasts at the ischemic boundary (Arvidsson et al., 2002; Parent et al., 2002; Jin et al., 2003; Zhang et al., 2004), suggesting that asymmetric division gives rise to neuroblasts that migrate to the ischemic striatum.

During neural development, Numb can direct asymmetric cell division. Our findings of Numb-positive cells in the SVZ suggest that Numb could play a role in the adult brain. However, although stroke transiently switches cell division from asymmetric to symmetric, Numb distribution did not change. Additional studies are warranted for determining the molecular basis underlying this cell division switch after stroke.

\section{References}

Alvarez-Buylla A, Garcia-Verdugo JM, Mateo AS, Merchant-Larios H (1998) Primary neural precursors and intermitotic nuclear migration in the ventricular zone of adult canaries. J Neurosci 18:1020-1037.

Arvidsson A, Collin T, Kirik D, Kokaia Z, Lindvall O (2002) Neuronal replacement from endogenous precursors in the adult brain after stroke. Nat Med 8:963-970.

Belliveau MJ, Cepko CL (1999) Extrinsic and intrinsic factors control the genesis of amacrine and cone cells in the rat retina. Development 126:555-566.

Berry M, Rogers AW (1965) The migration of neuroblasts in the developing cerebral cortex. J Anat 99:691-709.

Cai L, Hayes NL, Takahashi T, Caviness Jr VS, Nowakowski RS (2002) Size distribution of retrovirally marked lineages matches prediction from population measurements of cell cycle behavior. J Neurosci Res 69:731-744.

Caviness Jr VS, Takahashi T, Nowakowski RS (1995) Numbers, time and neocortical neuronogenesis: a general developmental and evolutionary model. Trends Neurosci 18:379-383.

Cayouette M, Whitmore AV, Jeffery G, Raff M (2001) Asymmetric segregation of Numb in retinal development and the influence of the pigmented epithelium. J Neurosci 21:5643-5651.

Chenn A, McConnell SK (1995) Cleavage orientation and the asymmetric inheritance of Notch1 immunoreactivity in mammalian neurogenesis. Cell 82:631-641.

Craig CG, Tropepe V, Morshead CM, Reynolds BA, Weiss S, van der Kooy D (1996) In vivo growth factor expansion of endogenous subependymal neural precursor cell populations in the adult mouse brain. J Neurosci 16:2649-2658.

Ericson J, Morton S, Kawakami A, Roelink H, Jessell TM (1996) Two critical periods of Sonic Hedgehog signaling required for the specification of motor neuron identity. Cell 87:661-673.

Haydar TF, Ang Jr E, Rakic P (2003) Mitotic spindle rotation and mode of cell division in the developing telencephalon. Proc Natl Acad Sci USA 100:2890-2895.

Hendzel MJ, Wei Y, Mancini MA, Van Hooser A, Ranalli T, Brinkley BR, Bazett-Jones DP, Allis CD (1997) Mitosis-specific phosphorylation of histone $\mathrm{H} 3$ initiates primarily within pericentromeric heterochromatin 
during G2 and spreads in an ordered fashion coincident with mitotic chromosome condensation. Chromosoma 106:348-360.

Hinds JW, Ruffett TL (1971) Cell proliferation in the neural tube: an electron microscopic and golgi analysis in the mouse cerebral vesicle. Z Zellforsch Mikrosk Anat 115:226-264.

Jin K, Sun Y, Xie L, Peel A, Mao XO, Batteur S, Greenberg DA (2003) Directed migration of neuronal precursors into the ischemic cerebral cortex and striatum. Mol Cell Neurosci 24:171-189.

Langman J, Guerrant RL, Freeman BG (1966) Behav of neuro-epithelial cells during closure of the neural tube. J Comp Neurol 127:399-411.

Lois C, Alvarez-Buylla A (1994) Long-distance neuronal migration in the adult mammalian brain. Science 264:1145-1148.

Luskin MB (1993) Restricted proliferation and migration of postnatally generated neurons derived from the forebrain subventricular zone. Neuron 11:173-189.

Martin AH (1967) Significance of mitotic spindle fibre orientation in the neural tube. Nature 216:1133-1134.

McConnell SK (1995) Constructing the cerebral cortex: neurogenesis and fate determination. Neuron 15:761-768.

McConnell SK, Kaznowski CE (1991) Cell cycle dependence of laminar determination in developing neocortex. Science 254:282-285.

Memberg SP, Hall AK (1995) Dividing neuron precursors express neuronspecific tubulin. J Neurobiol 27:26-43.

Menezes JR, Smith CM, Nelson KC, Luskin MB (1995) The division of neuronal progenitor cells during migration in the neonatal mammalian forebrain. Mol Cell Neurosci 6:496-508.

Morshead CM, Craig CG, van der Kooy D (1998) In vivo clonal analyses reveal the properties of endogenous neural stem cell proliferation in the adult mammalian forebrain. Development 125:2251-2261.

Murciano A, Zamora J, Lopez-Sanchez J, Frade JM (2002) Interkinetic nuclear movement may provide spatial clues to the regulation of neurogenesis. Mol Cell Neurosci 21:285-300.

Nakatomi H, Kuriu T, Okabe S, Yamamoto S, Hatano O, Kawahara N, Tamura A, Kirino T, Nakafuku M (2002) Regeneration of hippocampal pyramidal neurons after ischemic brain injury by recruitment of endogenous neural progenitors. Cell 110:429-441.

Parent JM, Vexler ZS, Gong C, Derugin N, Ferriero DM (2002) Rat forebrain neurogenesis and striatal neuron replacement after focal stroke. Ann Neurol 52:802-813.
Paxinos G, Watson C (1986) The rat brain in stereotaxic coordinates, Ed 2, xxvii. New York: Academic.

Petersen PH, Zou K, Hwang JK, Jan YN, Zhong W (2002) Progenitor cell maintenance requires numb and numblike during mouse neurogenesis. Nature 419:929-934.

Shen Q, Zhong W, Jan YN, Temple S (2002) Asymmetric Numb distribution is critical for asymmetric cell division of mouse cerebral cortical stem cells and neuroblasts. Development 129:4843-4853.

Smart IH (1973) Proliferative characteristics of the ependymal layer during the early development of the mouse neocortex: a pilot study based on recording the number, location and plane of cleavage of mitotic figures. J Anat 116:67-91.

Tramontin AD, Garcia-Verdugo JM, Lim DA, Alvarez-Buylla A (2003) Postnatal development of radial glia and the ventricular zone (VZ): a continuum of the neural stem cell compartment. Cereb Cortex 13:580-587.

Wakamatsu Y, Maynard TM, Jones SU, Weston JA (1999) NUMB localizes in the basal cortex of mitotic avian neuroepithelial cells and modulates neuronal differentiation by binding to NOTCH-1. Neuron 23:71-81.

Yoshimura S, Takagi Y, Harada J, Teramoto T, Thomas SS, Waeber C, Bakowska JC, Breakefield XO, Moskowitz MA (2001) FGF-2 regulation of neurogenesis in adult hippocampus after brain injury. Proc Natl Acad Sci USA 98:5874-5879.

Zhang R, Zhang Z, Wang L, Wang Y, Gousev A, Zhang L, Ho K, Morshead C, Chopp M (2004) Activated neural stem cells contribute to stroke induced neurogenesis and neuroblast migration towards the infarct boundary in adult rats. J Cereb Blood Flow Metab 24:441-448.

Zhang RL, Chopp M, Zhang ZG, Jiang Q, Ewing JR (1997) A rat model of embolic focal cerebral ischemia. Brain Res 766:83-92.

Zhang RL, Zhang ZG, Zhang L, Chopp M (2001) Proliferation and differentiation of progenitor cells in the cortex and the subventricular zone in the adult rat after focal cerebral ischemia. Neuroscience 105:33-41.

Zhong W, Feder JN, Jiang MM, Jan LY, Jan YN (1996) Asymmetric localization of a mammalian numb homolog during mouse cortical neurogenesis. Neuron 17:43-53.

Zhong W, Jiang MM, Weinmaster G, Jan LY, Jan YN (1997) Differential expression of mammalian Numb, Numblike and Notch1 suggests distinct roles during mouse cortical neurogenesis. Development 124:1887-1897.

Zhong W, Jiang MM, Schonemann MD, Meneses JJ, Pedersen RA, Jan LY, Jan YN (2000) Mouse numb is an essential gene involved in cortical neurogenesis. Proc Natl Acad Sci USA 97:6844-6849. 